\title{
THE ESTIMATION OF PHENOL AND CRESOL BY A BIOLOGICAL METHOD.
}

\author{
By M. WYNTER BLYTH, B.A., B.Sc., F.I.C., AND LEONARD GOODBAN. \\ (Read at the Meeting, April 10, 1907.)
}

THE estimation of phenol and the cresols is a matter of considerable importance, and one which is not easy to carry out unless the substances are pure and unmixed with each other. The estimation of phenol in commercial "carbolic acids" and in creasote, etc., is particularly difficult. In the present paper we record some observations made upon the germicidal powers of pure phenol, pure ortho-, meta-and paracresol, and mixtures of these on cultures of $B$. coli communis under defined conditions.

The principal object of our investigation was to obtain a method which can be applied to the estimation of the amount of phenol and cresylic acid in commercial carbolic acids and powders.

It has been shown by a number of observers that the germicidal value of cresylic acid is considerably greater than that of phenol; and it has been further shown by one of us (Journ. Soc. Chem. Ind., 1906, 25, 1183) that this difference in germicidal value between cresylic acid and phenol is very much reduced in the presence of organic matter containing either fat or albumin.

It became evident to us during these experiments that to ensure consistent results when working with micro-organisms two factors, in addition to the precautions usually taken, are of importance: (1) Temperature; (2) previous history of the organism.

(1) The temperature usually laid down is a room temperature of from $15^{\circ}$ to $18^{\circ} \mathrm{C}$. In exact work we find that we cannot allow any range of temperature, and our method of procedure is to make the necessary dilutions in fest-tubes, which are then placed in a water-bath at the exact temperature required for at least fifteen minutes before the experiment. The bath may have its side covered with felt, and the temperature is maintained by a small jet of gas and a thermostat in the ordinary way. During the experiment, when a test-tube is withdrawn to make an inoculation, it is replaced as rapidly as possible. 
(2) The directions as to age of culture are usually a twenty-four hours' old culture in standard broth. We find that repeated subcultures of organisms on artificial media lead to an attenuated growth, which is easily killed by the germicide, or if a culture be left at the room temperature for many days an attenuated growth results on taking the subculture.

More constant results are obtained if fresh organisms are isolated every few weeks from their natural medium-i.e., in the case of $B$. coli communis, from fæces. We also make a practice of testing the organism against an emulsified disinfectant with a high and known germicidal power, in order to ascertain if it has a normal resistance.

With due regard to reaction of broth, age and vigour of culture, and accurate temperature, the same results can be reproduced with the same germicide on different days, but only when these conditions are strictly adhered to.

In order to test the somewhat insoluble cresols under the same conditions as the soluble phenol, we adopt the following method of making dilutions:

To 5 grams of the phenol, cresol, or mixture of these substances are added, at $60^{\circ}$ C., 25 c.c. of a solution containing 10 grams of pure potassium soap (British Pharmacopceia) and 10 grams of pure resin soap; the flask is rotated and then made up to 100 c.c. with distilled water. With phenol and cresols a clear green solution is obtained, which, on further dilution with distilled water, tends to give a slightly turbid fluid or emulsion.

The effect of the soap mixture on the phenol is to raise its dilution figure* on the B. coli employed from about 80 to 130 , and on cresol to raise its figure from about 160 to 270 . This is probably due partly to the weakening effect of the soap on the organism, and partly to the more perfect distribution of the cresol throughout the mixture. Providing that there is sufficient soap in the mixture to form a perfect solution or emulsion, the actual quantity of soap mixture used is not of great importance. Phenol and cresols treated in this manner we shall refer to in this paper as emulsified phenol and cresol.

It has been said that a mixture of ortho-, meta-, and para-cresol has a higher germicidal value than have the individual constituents. It is true that ordinary socalled pure cresylic acid has when emulsified a higher germicidal value than pure freshly-distilled ortho-, meta-, or para-cresol; but it also has a higher germicidal value than a mixture of pure freshly-distilled ortho-, meta-, and para-cresol.

If commercially pure cresylic acid be distilled, the first portion of the distillate has, under the conditions of the test as applied by us, a lower germicidal value than freshly-distilled ortho-, meta-, or para-cresol, or any mixture of these bodies. This is without doubt due to the several samples of acid with which we worked containing a certain proportion of phenol. The second portion of the distillate has the same germicidal value as a mixture of ortho-, meta-, and para-cresol; but a residue is left in the retort which has a very much higher germicidal value than any mixture of ortho-, meta-, and para-cresol.

* Dilution figure D throughout this paper means that 1 part by weight of the germicide (phenol, cresol, etc.) in $\mathrm{D}$ parts of water killed the organism under the conditions of the experiment in twelve and a half minutes, but not in ten minutes. 
If we now take cresylic acid, and distil it so that a colourless distillate free from phenol is obtained, possessing a germicidal value equal to that of a mixture of freshly-distilled ortho-, meta-, and para-cresol, and we allow this distillate to remain exposed to the light and air until it becomes brown, it then has a higher germicidal value than it originally had, and again leaves in the retort a brown residue with a high germicidal value, so that if cresylic acid be taken as a standard in any way, we must make certain that it contains no phenol or higher homologues of the phenol series, and that it be distilled immediately before use.

The next point to be considered is whether there is any difference between the germicidal value of ortho-, meta-, and para-cresol. The results of our experiments tend to show that there is little, if any, difference between the germicidal value of these bodies. The following examples of our experiments upon this point may be taken in illustration, and although we have no evidence at present that phenol is influenced in the same way, as a precaution in making up phonol solutions we distil and collect a fraction of the distillate directly in a stoppered weighing bottle.

Twenty-four hours' culture of $B$. coli communis; broth, +15 ; temperature, $22^{\circ} \mathrm{C}$. Emulsified freshly-distilled ortho-, meta-, and para-cresol :

\begin{tabular}{|c|c|c|c|c|c|c|c|}
\hline \multirow{4}{*}{$\begin{array}{l}\text { Ortho- } \\
\text { cresol }\end{array}$} & ilutions by & $2 \frac{1}{2}$ & 5 & $7 \frac{1}{2}$ & 10 & $12 \frac{1}{2}$ & 15 \\
\hline & Weight. & Minutes. & Minutes. & Minutes. & Minutes. & Minutes. & Minutes. \\
\hline & 1.200 & $\begin{array}{l}+ \\
+\end{array}$ & $\begin{array}{l}+ \\
+\end{array}$ & $\bar{t}$ & - & - & - \\
\hline & 1.270 & + & + & + & + & - & - \\
\hline \multirow{3}{*}{$\begin{array}{l}\text { Meta- } \\
\text { cresol }\end{array}$} & $1 \cdot 260$ & + & + & - & - & - & - \\
\hline & $1 \cdot 265$ & + & + & + & - & - & - \\
\hline & 1.270 & + & + & + & + & - & - \\
\hline \multirow{3}{*}{$\begin{array}{l}\text { Para- } \\
\text { cresol }\end{array}$} & $1 \cdot 260$ & + & + & + & - & - & - \\
\hline & $1 \cdot 265$ & + & + & + & + & - & - \\
\hline & $1 \cdot 270$ & + & + & + & + & + & - \\
\hline
\end{tabular}

This result was confirmed by several other experiments, para-cresol being always a little less active than either ortho- or meta-cresol. We could find no difference in germicidal value between ortho- and meta-cresols. On mixing the three cresols a value was obtained which indicated that mixing the sample of cresols has no influence on their germicidal value, or one so small as to be impossible of detection. The difference between the germicidal value of ortho-, meta-, and para-cresol is so small that in equal mixtures of these bodies the mean value comes out the same as with either ortho-, or meta-cresol, so that for practical purposes we take as a standard cresol a mixture prepared from the pure, freshly-distilled bodies. This is far more accurate than taking cresylic acid, which is rarely, if ever, free from other substances, as already pointed out.

In our experiments and under our conditions we found the mean dilution figure (by weight) for pure, freshly-distilled, emulsified ortho-, meta-, and para-cresol to be 270 , when phenol under the same conditions had a dilution figure of 130 . We further found that when mixtures were made of the distilled cresols and phenol, the dilution figure obtained was strictly in accordance with the composition of the mixture, and that the percentage of phenol and cresol could be calculated from the following formula: 
If $\mathrm{P}=$ per cent. of phenol

$\mathrm{D}_{1}=$ the dilution figure for ortho-, meta-, and para-cresol

$\mathrm{D}_{2}=$ the dilution figure for phenol

$\mathrm{D}_{3}=$ the dilution figure found for the mixture,

$$
\text { (1.) Then } \mathrm{P}=\frac{100\left(\mathrm{D}_{1}-\mathrm{D}_{3}\right)}{\mathrm{D}_{1}-\mathrm{D}_{2}} \text {. }
$$

It is important to notice that a determination may be made at almost any temperature and with any organism, and the details of the experiment and the method of getting the cresols and phenols in solution may be varied largely at the will of the operator, providing he carries out all his determinations under standard conditions. The figures given here for cresols and phenol only represent what were obtained under our conditions.

We find that in using this method it is possible to appreciate as little as 2 per cent. of phenol in a cresol mixture. To do this the mixture is distilled. If 100 c.c. be taken, the whole of the phenol comes over, in the first 25 c.c. of the distillate. This distillate is then examined for its dilution figures, when we find a drop in the dilution figure of at least 10. Larger quantities of phenol can be estimated in this manner with very considerable accuracy.

Under ordinary circumstances we hardly ever have to determine dry phenol in dry cresols; there is nearly always a small amount of water present, and the method above described would not be applicable to mixtures containing water. In order to determine water at the same time as phenol, we utilize the fact that organic matter lowers the germicidal efficiency of emulsified coal-tar disinfectants. The organic matter we introduce in the form of milk. We use milk because, besides finding no objections or drawbacks to its use, we have been unable to find anything that can be conveniently substituted for it. Why organic matter should lower the efficiency of a disinfectant is by no means clear; probably it is partly owing to the effect it has upon the emulsion; but many normal and acid salts and acids which throw the soaps out of solution do not lower the efficiency, nor does the acidity of the milk seem to greatly influence the result. The problem is, of course, complicated by the weakening effect that such acids and salts may have upon the organism.

Using pure, freshly-distilled, emulsified phenol, we find that if 5 c.c. of milk ( 1 per cent. fat, acidity $20^{\circ}$ to $25^{\circ}$ ) be introduced into the test as previously described (Axalyst, 1906, 31, 150), the dilution figure is lowered from 130 in water to 90 in the milk-a drop of 40 . Using in the same way ortho-, meta-, and para-cresol, we obtained the following results :

\begin{tabular}{|c|c|c|c|c|c|}
\hline & & & $\begin{array}{l}\text { Water Dilution } \\
\text { Figure, D. }\end{array}$ & $\begin{array}{l}\text { Wilk Dilution } \\
\text { Figure, M. }\end{array}$ & $\begin{array}{c}\text { Difference, } \\
\mathrm{K} .\end{array}$ \\
\hline Ortho-cresol & & $\cdots$ & 270 & 170 & \\
\hline Meta-cresol & $\ldots$ & $\ldots$ & 270 & 170 & 100 \\
\hline Para-cresol & $\ldots$ & $\ldots$ & $\ldots \quad 265$ & 165 & 100 \\
\hline Phenol ... & $\ldots$ & $\ldots$ & $\ldots \quad 130$ & 90 & 40 \\
\hline
\end{tabular}

It is interesting to note that the slight difference which exists between the germicidal value of para-cresol and ortho-, and meta-cresols is still maintained in the 
presence of organic matter, but that this causes its drop of efficiency to be exactly the same as that obtained in the case of the other two.

Now it is obvious that if we have a mixture of phenol, cresols, and water, that the difference in the dilution figure obtained in water and in milk will depend on the actual amount of phenol and cresol present, and that from these figures it is possible to calculate the phenol, the cresol, and the water.

TAR.-If we call $x$ the total percentage of phenol and cresol present in our mixture, then if we take an apparent dilution $\mathrm{D}_{3}$ of this mixture, the real dilution used is represented by $\frac{100 \mathrm{D}_{3}}{x}$. And if $\mathrm{K}_{1}$ is the difference observed between the water figure $D_{1}$ and the milk figure $M_{1}$ for pure cresols, $K_{2}$ the difference between the water and milk figures for phenol, and $\mathrm{K}_{3}$ the apparent difference between the water and milk figures of our sample, then-

$$
\text { (2.) } x=\frac{100 \mathrm{D}_{3}\left(\mathrm{~K}_{1}-\mathrm{K}_{2}\right)-100 \mathrm{~K}_{3}\left(\mathrm{D}_{1}-\mathrm{D}_{2}\right)}{\mathrm{K}_{1} \mathrm{D}_{2}-\mathrm{K}_{2} \mathrm{D}_{1}} \text {. }
$$

Example.-A mixture of phenol, cresols, and water was found to have a dilution figure in water of 173 , and in milk a dilution figure of 113 . The phenol and cresol figures being as before, then-

$$
\begin{array}{ccccc}
\text { Water. } & & \text { Milk. } & & \text { Difference. } \\
\mathrm{D}_{1}=270 & \ldots & \mathrm{M}_{1}=170 & \ldots & \mathrm{K}_{1}=100 \\
\mathrm{D}_{2}=130 & \ldots & \mathrm{M}_{2}=90 & \ldots & \mathrm{K}_{2}=90 \\
\mathrm{D}_{3}=173 & \ldots & \mathrm{M}_{3}=113 & \ldots & \mathrm{K}_{3}=60
\end{array}
$$

Applying formula 2, $x=90$. There was present 90 per cent. of phenol and cresols. Therefore our true dilution in water was-

$$
\mathrm{D}_{3}=\frac{173 \times 100}{90}
$$

and by applying formula $1, \mathrm{P}=55.5$ per cent. of the total phenol and cresol present, or 50 per cent. of our mixture, which consists of 50 per cent. phenol, 40 per cent. cresol, and 10 per cent. water.

In applying this method the actual composition of the milk is not of importance, providing that sufficient be sterilised in the first place to carry out the determinations on the sample itself and on the controls, which must be done under exactly the same conditions. The more fat there is in the milk the greater will be the difference in drop between the cresols and phenol; but this advantage is counterbalanced by the tendency of fat in milk to rise. On this account we prefer to use a milk poor in fat, or separated milk.

The organism used and the temperature, as well as the other details, may vary very considerably, according to individual preference; but for each set of determinations all these details must be kept absolutely the same.

\section{Discussion.}

The Chatrman (Mr. W. W. Fisher, M.A.) said he had been struck by the complexity of the problem which the authors were attacking. In regard to the composition of the materials brought into the reactions, there were apparently many 
variable factors which had to be more or less carefully standardised. He should have thought that it would have been necessary, for the information of others using the process, to define the soaps a little more precisely.

Mr. Chapman asked if it was possible always to get the same type of Bacillus coli from fæces-in other words, to get a standard organism. There were many organisms of the $B$. coli group which resembled one another somewhat closely, but which might differ considerably in their resistance to carbolic acid and cresol.

Mr. W . PARTRIDGE remarked that Mr. Wynter Blyth on a previous occasion had shown that the drop in the coefficient which occurred when milk was used was due to the fat and proteid matter. Seeing that separated milk would contain only about $0 \cdot 2$ per cent. of fat, would it not be equally satisfactory simply to use a solution of some protein substance?

Mr. R. A. CRIPPS said that the necessity for an exact definition of the soap was indicated by the fact that a good deal of the soap sold as B.P. hard soap was cocoanut-oil soap; and, although he had not met with many soft soaps containing cocoanut oil, it seemed likely that, having been used in hard soap, it would soon be used in soft soap also.

Mr. Bevan asked if it was not important whether the soap was neutral or whether it contained much free alkali.

Mr. Wynter BLyth, in reply, said that it did not matter what kind of soap was used, provided that exactly the same conditions as to soap, temperature, and organism were applied to the pure phenol and cresol and to the samples to be tested. The soaps they had actually used were the green potash soap of the B.P. and the purest resin soap obtainable. The latter probably was not greatly liable to adulteration, being, indeed, itself used as an adulterant. It was, of course, necessary to see that the soap was neutral. For the process now described it was not important to have a standard organism, but in connection with the standardisation of disinfectants this was the great difficulty, as the coli organisms varied very greatly. He was in the habit of using a disinfectant of high and known germicidal value as an extra control. He agreed that it was not possible to get a really standard organism. The object of their work in connection with this paper was to obtain a method applicable to commercial carbolic acids and powders, which were often sold at prices incompatible with the presence of the alleged quantities of phenol and cresol. They had found it necessary to proceed step by step, ascertaining first what could be done with known mixtures of the pure substances. With regard to the possibility of making artificial mixtures of fat and albumin, experiments had proved that such mixtures were not so satisfactory as milk.

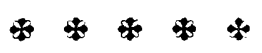

